\title{
Severe forms of fibromyalgia with acute exacerbation of pain: costs, comorbidities, and length of stay in inpatient care
}

This article was published in the following Dove Press journal:

ClinicoEconomics and Outcomes Research

I June 2017

Number of times this article has been viewed

\author{
Tobias Romeyke ${ }^{1,2}$ \\ Elisabeth Noehammer ${ }^{1}$ \\ Hans Christoph Scheuer ${ }^{2}$ \\ Harald Stummer ${ }^{1,3}$ \\ 'Institute for Management and \\ Economics in Health Care, \\ University of Health Sciences, Medical \\ Informatics and Technology (UMIT), \\ Hall in Tirol, Austria; ${ }^{2}$ Waldhausklinik \\ Deuringen, Acute Hospital for \\ Internal Medicine, Pain Therapy, \\ Complementary, and Individualized \\ Patient-Centered Medicine, \\ Stadtbergen, Germany; ${ }^{3}$ nstitute \\ for Management and Innovation \\ in Healthcare, University Schloss \\ Seeburg, Seekirchen/Wallersee, \\ Austria
}

Background and purpose: As a disease of the musculoskeletal system, fibromyalgia is becoming increasingly important, because of the direct and indirect costs to health systems. The purpose of this study of health economics was to obtain information about staff costs differentiated by service provider, and staff and material costs of the nonmedical infrastructure in inpatient care. Patients and methods: This study looked at 263 patients who received interdisciplinary inpatient treatment for severe forms of fibromyalgia with acute exacerbation of pain between 2011 and 2014. Standardized cost accounting and an analysis of additional diagnoses were performed. Results: The average cost per patient was $€ 3,725.84$, with staff and material costs of the nonmedical infrastructure and staff costs of doctors and nurses accounting for the highest proportions of the costs. Each fibromyalgia patient had an average of 6.1 additional diagnoses.

Conclusion: Severe forms of fibromyalgia are accompanied by many concomitant diseases and associated with both high clinical staff costs and high medical and nonmedical infrastructure costs. Indication-based cost calculations provide important information for health policy and hospital managers if they include all elements that incur costs in both a differentiated and standardized way.

Keywords: fibromyalgia, DRG, cost, length of stay, comorbidities, interdisciplinary care, inpatient care, musculoskeletal, pain

\section{Background and purpose}

Fibromyalgia is a pain disorder listed as M79.70 in the International Classification of Diseases (ICD). Patients with fibromyalgia syndrome (FMS) report diffuse (musculoskeletal) pain all over their body and many symptoms. ${ }^{1}$ These often include muscle and joint pain in all areas of the body, and often also stiffness, poor concentration, mood swings, general exhaustion, chronic fatigue, sleep disorders, irritable bowel syndrome, anxiety, and depression. ${ }^{2,3}$ In addition, patients often have symptoms of cardiovascular dysregulation and dizziness, increased sweating, and cold hands and feet.

Diagnosis is difficult and the cause of fibromyalgia unclear. An increase in systemic proinflammatory cytokines and a potentially hyporeactive hypothalamic-pituitaryadrenal axis are among the causes currently being discussed. ${ }^{4}$ With reasons uncertain, there are many varied approaches to treatment. Multimodal treatment under inpatient conditions has proven to be effective for the complex and multilayered pattern of symptoms associated with fibromyalgia..$^{5-8}$

Research on fibromyalgia and its treatment is becoming increasingly important, because of the direct and indirect costs incurred by health systems. ${ }^{9-12}$ Studies show
Correspondence: Tobias Romeyke Institute for Management and Economics in Health Care, University of Health Sciences, Medical Informatics and Technology (UMIT), I Eduard-WallnöferZentrum, Hall in Tirol 6060, Austria Tel +43508648 387!

Fax +43508648 673 87I

Email tobias.romeyke@umit.at 
that cases of FMS incur higher costs, eg, than other rheumatic disorders. ${ }^{13,14}$ Delays in the diagnosis of FMS can increase the economic cost even further. ${ }^{15}$ Studies show that patients with fibromyalgia often face a long road to diagnosis, ${ }^{16,17}$ even though early diagnosis can reduce the cost to health systems. ${ }^{16}$ The purpose of this study was to calculate and analyze the costs of inpatient treatment using standardized cost accounting and to obtain information about disorders that accompany FMS.

\section{Patients and methods}

This study did not use individually identifiable patient data. All primary data presented in the results section were derived from administrative databases. Approval from an Institutional Review Board and patient's written informed consent to conduct this study were not necessary, because the data were collected for administrative or billing purposes and no patient can be identified. In the following sections, we describe how costs were calculated and treatment needs assessed.

\section{Calculating inpatient costs}

The Kalkulationshandbuch (calculation manual for use in hospitals, version 3.0 - July 10, 2007) was used to calculate the cost of treating FMS patients. The calculation methods were pretested in German hospitals. Between 2010 and 2014, these methods were then used to calculate the costs of around 20 million hospital cases of different diagnoses in Germany. ${ }^{18}$ The calculation of case costs is based on the actual costs shown in the audited annual accounts of the hospital.

In a structured cost calculation, service and structural data are collected in accordance with the German Hospital Remuneration Act. Cost data are also collected and broken down into cost center, unit, and case-based service data. In this cost analysis, this included German nursing staff regulation minutes. These distinguish among different care categories based on age and level of care. The levels of care are general care (A) and special care (S), which then are further subdivided into degrees. A1 covers all services for patients with no particular care needs. A2 indicates patients who need help in at least two areas, eg, help with standing up, going to the toilet, and cutting food. A3 patients need full care in at least three areas, eg, full body wash, positioning, incontinence care, and supervision when disoriented. $\mathrm{S} 1$ covers minor additional-care services that are not covered by S2 or S3 (eg, daily blood pressure measurement). Having to supervise only one more complexcare service is classed as S2 (dressing change, supervising the taking of medication). A case is categorized as S3 if at least one complex-care service is provided (eg, monitoring patients with side effects of medication).
Costs that are not relevant are not included in the cost calculation, ie, costs that are not linked to the German Diagnosis-Related Group (G-DRG) system are deducted from the total costs of the hospital for both cost-unit and cost-center accounting. This is done on a cost-unit basis by deducting costs relating to other periods. Deductions are also made at cost-center level, eg, the corresponding proportion of a cost center is deducted if outpatients or external patients were also treated there. In this cost calculation, a distinction is made between direct and indirect cost centers. Direct cost centers provide their services directly to the patient. These are mainly examination and treatment services. Indirect cost centers provide their services to direct cost centers rather than individual patients, eg, bed preparation, business and supply services, and administration. The costs of these indirect cost centers are allocated to direct cost centers using allocation keys based on causation. Individual costs are assigned directly to the relevant case in the calculation and thus taken out of cost-center accounting, in order to avoid duplication.

The in-house service-allocation system is used for cost-center accounting. Ultimately, the allocated costs of the medical and nonmedical infrastructure are shown in every direct cost center and then assigned to individual treatment cases using the corresponding case-based reference values.

\section{Need for inpatient treatment}

Patients were referred to inpatient treatment by a specialist or general practitioner when unimodal approaches to the treatment of FMS pain were no longer yielding results. The need for inpatient treatment was then assessed by rheumatologists, specialists in general medicine, and specialists in specific pain therapy at the time of admission to hospital.

Furthermore, the Gerbershagen et al classification system (Mainz Pain Staging System [MPSS]), ${ }^{19}$ which is a questionnaire for the patient, was used to assess the need for inpatient treatment. It consists of five different axes, each divided into three stages. Stage I shows the best prognosis, whereas stage III covers the most severe pain disorders. In the questionnaire, patients are asked about temporal aspects of the pain. This includes the frequency and duration of the pain and changes in intensity. Spatial aspects of the pain, eg, location, are also ascertained. In addition, the classification is influenced by information about the use of medication. If a patient has chronic pain classified as stage II or III in the MPSS, an inpatient stay lasting at least 2 weeks is considered constructive. The aim of the MPSS is to identify the stage 
of chronicity that the patient has reached and the treatment that is needed. In their study on the operationalization of the MPSS, Gerbershagen et al concluded that in stages II and III, neither monodisciplinary medical nor monodisciplinary psychological treatment is useful. ${ }^{19}$ In summary, this system for classifying the chronicity of pain is a multidimensional one from which both the symptoms and how the patient handles the disease can be deduced.

Patient-related assessments were also performed and the results fed into the specialists' decision-making process. A visual analog scale was used to measure, among other things, pain, ${ }^{20}$ well-being, ${ }^{21}$ and sleep disorders caused by pain..$^{22}$ To measure the psychological comorbidity of FMS, the Patient Health Questionnaire 9 score of every patient was used as a psychodiagnostic tool. ${ }^{23}$ Functional limitations were ascertained using the Hannover Functional Ability Questionnaire. ${ }^{24,25}$ Finally, all patient data relating to the case are recorded. This includes changes in personal physician, pain-related hospital stays and operations, and pain-related rehabilitation received. All tests and data used for assessing acute inpatient-treatment needs are shown in Figure 1.

\section{Inclusion criteria for interdisciplinary patient-centered care}

Decisive for being selected for an interdisciplinary patientcentered treatment for fibromyalgia is the fulfillment of certain inclusion criteria regarding the patient. These are shown in Table 1, and are checked for after being diagnosed with FMS. All patients included in the present study were surveyed as per these criteria to determine the severity of the illness and thus the necessity of inpatient treatment. ${ }^{26}$ Only patients who fulfilled all criteria, thereby qualifying for inpatient treatment, were included in the standardized cost calculation.

Interdisciplinary patient-centered care for FMS patients can comprise three complex treatments: multimodal complex rheumatologic treatment (OPS 8-983), multimodal pain management (OPS 8-918), and naturopathic complex therapy (OPS 8-975). The codes in parentheses refer to the standards on which these approaches are based (Operationen- und Prozedurenschlüssel [OPS]). All three were applied for FMS patients during the study.

\section{Results}

The study included 263 patients who received inpatient treatment in a specialized clinic for the principal diagnosis of fibromyalgia between 2011 and 2014. The inclusion criteria were the criteria described above in the "Patients and methods" section, which indicated a severe form of FMS that was resistant to outpatient treatment. Of all patients included in the study, 247 were female and eleven male. The majority of the patients (about 77\%) in this study had an average

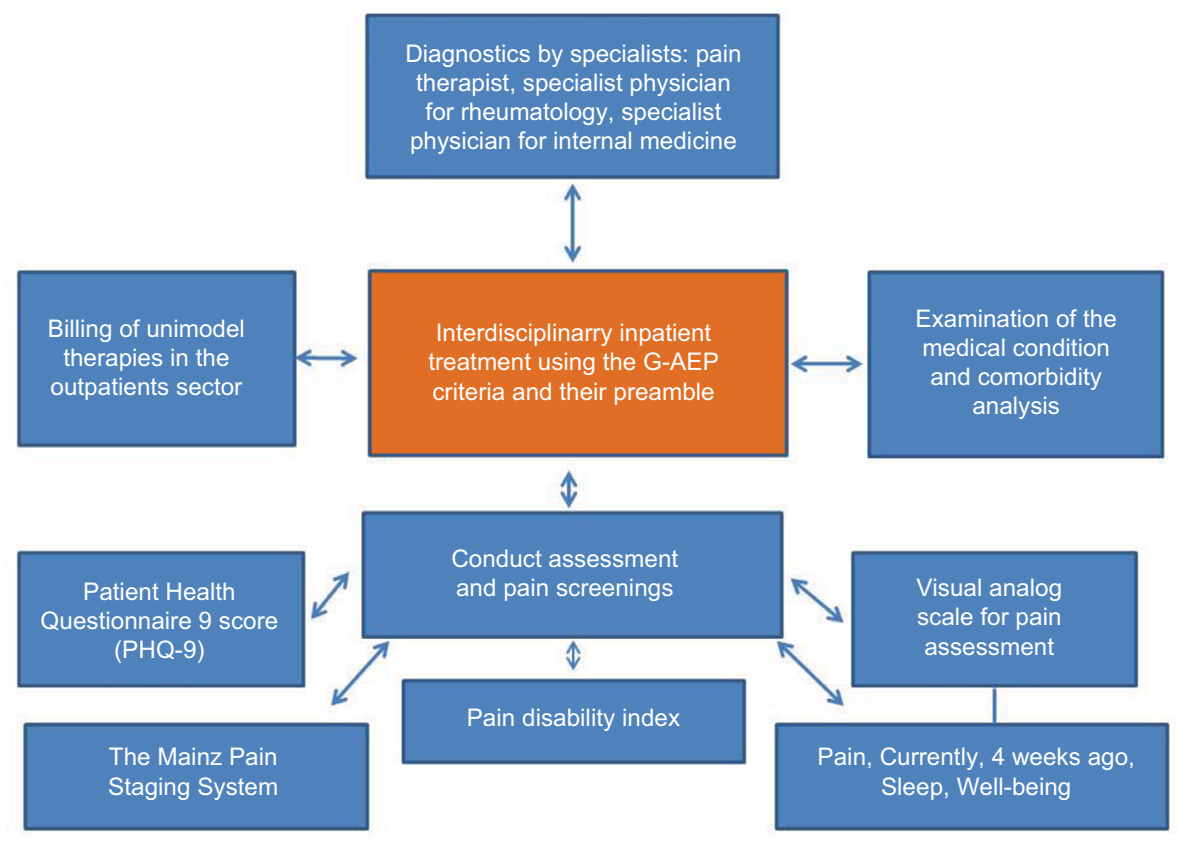

Figure I Acute inpatient treatment: patient-specific examinations. Abbreviation: G-AEP, German appropriateness-evaluation protocol. 
Table I Patient-related inclusion criteria for interdisciplinary patient-centered care

\begin{tabular}{|c|c|c|}
\hline $\begin{array}{l}\text { Multimodal complex rheumatologic } \\
\text { treatment, OPS 8-983 }\end{array}$ & $\begin{array}{l}\text { Multimodal pain management, OPS } \\
8-918\end{array}$ & Naturopathic complex therapy, OPS 8-975 \\
\hline Path entry criteria: defined by the hospital & $\begin{array}{l}\text { Path entry criteria: defined in German } \\
\text { operation and procedure code } \\
\text { (Operationen- und Prozedurenschlüssel } \\
\text { [OPS]) }\end{array}$ & $\begin{array}{l}\text { Path entry criteria: the guidelines }{ }^{46} \text { represent the } \\
\text { current state of naturopathic specialist opinion } \\
\text { as to which conditions are generally necessary } \\
\text { such that a chronically ill patient will be admitted } \\
\text { to hospital for inpatient naturopathic complex } \\
\text { therapy }{ }^{47}\end{array}$ \\
\hline Reduced functional capacity & $\begin{array}{l}\text { Manifest or threatening impairment of } \\
\text { quality of life and/or ability to work }\end{array}$ & $\begin{array}{l}\text { It must be ensured that it would not be possible } \\
\text { to achieve the therapeutic target by means of } \\
\text { inpatient rehabilitation }\end{array}$ \\
\hline Activity of rheumatic disease & $\begin{array}{l}\text { Failure of a previous unimodal pain } \\
\text { therapy, a pain-related operative } \\
\text { intervention, or a withdrawal therapy }\end{array}$ & $\begin{array}{l}\text { The degree of chronicity must be evaluated } \\
\text { analogously to the Mainz stage model of pain } \\
\text { chronicity (Mainz Pain Staging System), referring to } \\
\text { the individual type and intensity of the symptoms }\end{array}$ \\
\hline $\begin{array}{l}\text { Manifest or threatening impairment of } \\
\text { quality of life and/or ability to work }\end{array}$ & Existing drug dependence or drug misuse & $\begin{array}{l}\text { The symptomatic intensity should be evaluated, } \\
\text { eg, analogously to the von Korff model for chronic } \\
\text { complaints, referring to the individual type and } \\
\text { intensity of the symptoms }\end{array}$ \\
\hline \multirow[t]{2}{*}{ Multiple pain } & Serious concomitant mental disorder & $\begin{array}{l}\text { The clinical picture involves at least three different } \\
\text { sections of the International Classification of Diseases }\end{array}$ \\
\hline & Serious concomitant somatic disease & \\
\hline
\end{tabular}

Note: Data from Romeyke and Stummer. ${ }^{26}$

length of stay of $10-14$ days $(\geq 10-<15)$. The average age of the patients was 54.78 years.

The assessment results revealed chronicity stages of 2 and 3 (MPSS). All patients were found to have greater $(\mathrm{x}<60 \%)$ physical limitations, as measured by the Hannover Functional Ability Questionnaire. The well-being of all patients was significantly reduced, and the average intensity of the pain was $7 / 10$ (visual analog scale).

\section{Diagnoses}

In accordance with the German coding guidelines, "the diagnosis identified in the analysis as primarily responsible for the patient's inpatient stay" was coded as the principal diagnosis. The phrase "in the analysis" refers to the evaluation of the findings at the end of the inpatient stay, in order to establish which disease was primarily responsible for the inpatient stay. The evaluated findings can include information obtained from the medical and care history, a psychiatric examination, consultations with specialists, a physical examination, diagnostic tests or procedures, surgical procedures, and pathological or radiological examinations.

Based on the ICD, an analysis of the concomitant diseases of each patient revealed 1,572 additional diagnoses for all subjects, ie, an average of 6.1 additional diagnoses per patient, to the principal diagnosis of FMS. The additional diagnoses were coded in accordance with the German coding guidelines for diseases. According to these guidelines, an additional diagnosis is defined as "a disease or condition that either exists at the same time as the principal diagnosis or develops during the hospital stay". Additional diagnoses were interpreted as diseases that influence patient management in such a way that therapeutic and/or diagnostic measures and higher levels of nursing care are required.

In the analysis of additional diagnoses in accordance with the ICD (Table 2), "diseases of the musculoskeletal system and connective tissue" were the most common. These included low-back pain, low-back pain with sciatica, and spondylosis experienced at the same time as the FMS. There were 285 additional diagnoses among "endocrine, nutritional, and metabolic diseases". These included obesity, diabetes mellitus, and food intolerances, such as fructose and lactose malabsorption. The 225 additional diagnoses in the "mental and behavioral disorders" category included depression, anxiety, dysthymia, and sleep disorders. Diseases of the nervous system were diagnosed 218 times, and included headache, cervicocranial syndrome, and radiculopathy. The 114 diagnoses in the "diseases of the circulatory system" category were dominated by hypertension and cardiovascular diseases (Table 2).

\section{Costs}

The average cost of inpatient stay was $€ 3,740.00$ per patient. Comprehensive standardized cost accounting was used to allocate costs to cost categories. Eight cost categories were 
Table 2 Analysis of additional FMS diagnoses in accordance with the International Statistical Classification of Diseases and Related Health Problems, tenth revision

\begin{tabular}{|c|c|c|c|}
\hline Chapter & Block & $\mathbf{n}$ & Title \\
\hline 1 & A00-B99 & 7 & Certain infectious and parasitic diseases \\
\hline II & C00-D48 & 3 & Neoplasms \\
\hline III & D50-D89 & 17 & Diseases of the blood and blood-forming organs and certain disorders involving the immune mechanism \\
\hline IV & E00-E90 & 285 & Endocrine, nutritional, and metabolic diseases \\
\hline $\mathrm{V}$ & F00-F99 & 225 & Mental and behavioral disorders \\
\hline $\mathrm{VI}$ & G00-G99 & 218 & Diseases of the nervous system \\
\hline VII & $\mathrm{H} 00-\mathrm{H} 59$ & II & Diseases of the eye and adnexa \\
\hline VIII & $\mathrm{H} 60-\mathrm{H} 95$ & 12 & Diseases of the ear and mastoid process \\
\hline IX & $100-199$ & 114 & Diseases of the circulatory system \\
\hline$x$ & J00-J99 & 39 & Diseases of the respiratory system \\
\hline $\mathrm{XI}$ & K00-K93 & 53 & Diseases of the digestive system \\
\hline XII & L00-L99 & 10 & Diseases of the skin and subcutaneous tissue \\
\hline XIII & M00-M99 & 420 & Diseases of the musculoskeletal system and connective tissue \\
\hline XIV & N00-N99 & 28 & Diseases of the genitourinary system \\
\hline $\mathrm{XV}$ & O00-099 & 0 & Pregnancy, childbirth, and the puerperium \\
\hline $\mathrm{XVI}$ & P00-P96 & 0 & Certain conditions originating in the perinatal period \\
\hline $\mathrm{XVII}$ & Q00-Q99 & 3 & Congenital malformations, deformations, and chromosomal abnormalities \\
\hline XVIII & R00-R99 & 72 & Symptoms, signs, and abnormal clinical and laboratory findings not elsewhere classified \\
\hline $\mathrm{XIX}$ & S00-T98 & 19 & Injury, poisoning, and certain other consequences of external causes \\
\hline$x X$ & V0I-Y98 & 0 & External causes of morbidity and mortality \\
\hline $\mathrm{XXI}$ & Z00-Z99 & 36 & Factors influencing health status and contact with health services \\
\hline XXII & U00-U85 & 0 & Codes for special purposes \\
\hline
\end{tabular}

Abbreviation: FMS, fibromyalgia syndrome.

analyzed, and their share of the total costs are shown in Figure 2. In cost category 1 , an average cost of $€ 822.34$ was calculated for the treatment of an FMS patient regarding physician service. This includes the staff costs for doctors, statutory social security contributions and pension contributions, and other staff costs and fees for doctors not employed by the hospital.

Cost category 2 covers nursing-staff costs. This includes statutory social security contributions, pension contributions, and other staff costs. On average, the total cost of nursing for an FMS patient was $€ 739$.54. Staff costs for medical technicians/non-ward-based nurses are included in cost category 3. This covers statutory social security contributions, pension contributions, and other staff costs. On average, the total cost of care for an FMS patient was $€ 249.67$ in this category.

Cost categories 4A and $\mathrm{B}$ include material costs for medicinal products, hospital-pharmacy delivery costs, and those relating to medical need for blood, packed red cells, and blood plasma. The average cost in this category was $€ 54.15$. Cost categories $6 \mathrm{~A}$ and $\mathrm{B}$ include material costs for "other medical needs". A distinction is made between
A (average cost of €30.19) and B (average cost of €66.80), because $6 \mathrm{~B}$ includes individual costs in the material costs for other medical needs. Cost categories $6 \mathrm{~A}$ and $\mathrm{B}$ cover dressings, remedies, and aids, medical and nursing consumables, and radiology and nuclear medicine, as well as laboratory services. They also cover tests in external departments, electroencephalography, electrocardiography, ultrasound, physiotherapy, disinfectants, and other medical needs. Cost category 7 covers "staff and material costs of the medical infrastructure", and includes the cost of transporting patients, medical care in the community, maintaining medical technology, and depreciation of replaced medical durables. The average total cost per patient in this group was $€ 340.83$.

For cost category 8 , the average cost per patient was $€ 1,401.50$. This category accounts for the highest proportion of the cost of inpatient care. It includes "staff and material costs of the nonmedical infrastructure", ie, the salaries, statutory social security contributions and pension contributions of clinical hospital staff and staff providing business and supply services, technical services, administrative services, and special services, and staff costs that cannot be allocated 

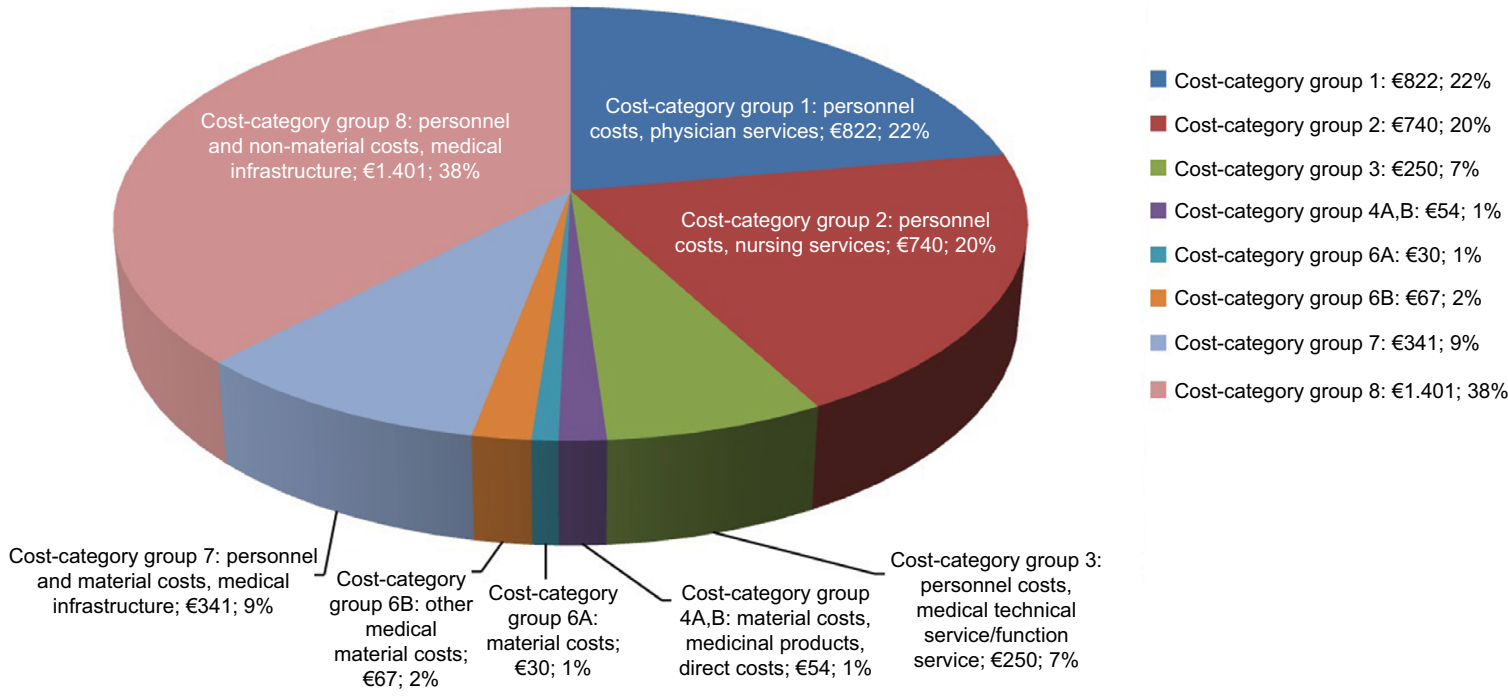

Figure 2 Average costs per cost-category group.

elsewhere. It also includes the cost of food, water, electricity, fuel, materials, cleaning products and disinfectants, linen, laundry cleaning and care, household consumables, crockery, fuel, lubricants, and garden maintenance. Moreover, maintenance cleaning and laundry cleaning by external companies, administrative services, office materials and printing, postage, Post Office box and bank fees, light freight, telephone systems and telex machines, telegrams, radio and television, travel expenses, fares, recruitment costs, consulting fees, audit, court and legal fees, contributions to organizations, hospitality, IT and organizational expenses, central administration, and central personnel management are also included. Category 8 also includes the cost of the central printing service, central technical services, replacing durables (provided fixed values were given), taxes, duties, insurance, interest and similar expenses for operating loans, depreciation of other durables, and ordinary expenditure, such as rent, leases, licenses, carriage for delivery of goods, material expenses for training and development, and renting durables.

The distribution of average total costs on cases is shown in Figure 3. The majority of patients incurred average costs of $€ 4,102.14-€ 4,664.04$, closely followed by a second group incurring $€ 2,995.30-€ 3,498$.44. Patients leaving the hospital earlier than anticipated due to "other reasons" produced costs below $€ 2,987$. The most expensive cases, resulting in costs of above $€ 4,674$, required more therapies and were longer in hospital, due to lasting pain and relevant functional limitations. These cases were analyzed regarding secondary diagnoses. We found the following to be the most common: diseases of the musculoskeletal system and connective tissue, endocrine, nutritional, and metabolic diseases, and mental and behavioral disorders. Additional diagnoses are shown in Figure 4, and are coded according to the ICD- 10 .

However, random-sample analyses showed that the number of additional diagnoses of a patient with fibromyalgia was not associated with higher costs. There was no causal relationship between the length of stay in hospital and the number of concomitant diseases either. Instead, physical limitations, high therapy-resistant pain intensity, and progression of chronicity were more likely to have an effect.

\section{Discussion}

Patients with severe forms of fibromyalgia are recommended multimodal treatments in an inpatient setting. ${ }^{27}$ For milder forms, the guidelines state that individual treatment methods in outpatient settings should be administered first. ${ }^{28}$ The FMS patients included in this study had severe forms, and a multimodal interdisciplinary approach to their treatment involving various specialists, nurses, and therapists was taken. ${ }^{26}$

Several previous studies have focused on the costs arising from fibromyalgia. ${ }^{29-32}$ Cost comparisons of FMS and other diagnoses, eg, diabetes are available, ${ }^{33}$ as is a longitudinal evaluation of health care utilization and costs during the first 3 years after a new diagnosis of fibromyalgia. ${ }^{34}$ Nevertheless, to date there has been no detailed cost analysis to include all professional groups and material costs ${ }^{35}$ and differentiate 


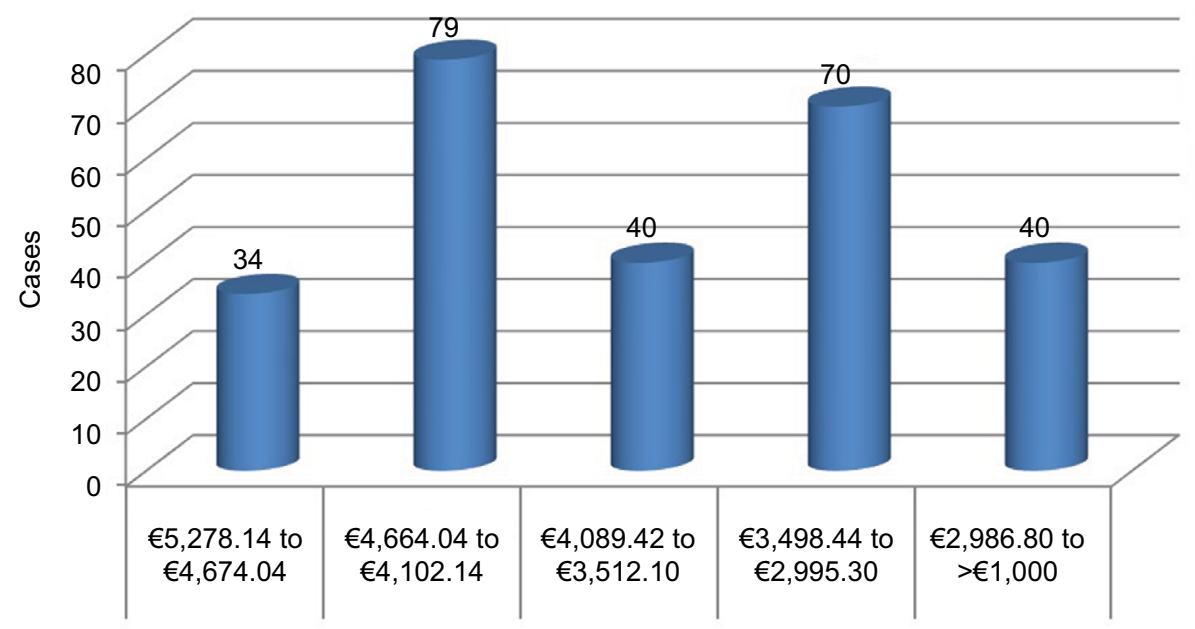

Figure 3 Distribution of average total costs.

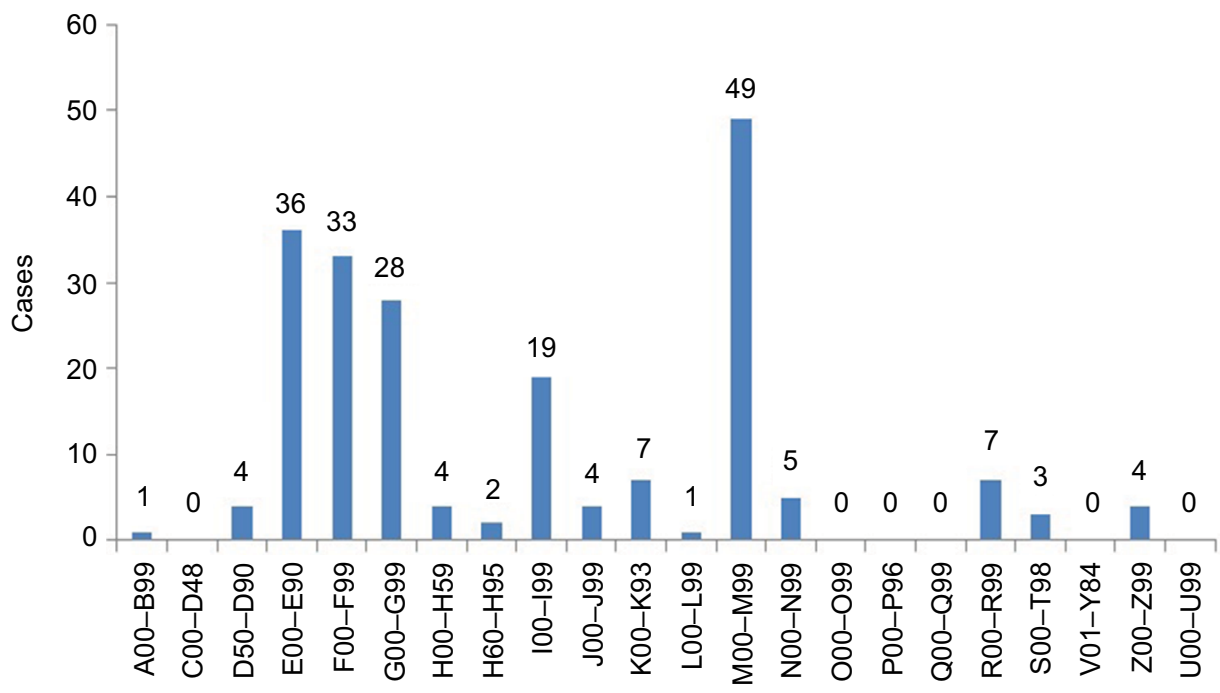

Figure 4 Additional fibromyalgia-syndrome diagnoses in the cost-driving group.

them for the care of FMS patients with severe forms in an acute-inpatient setting with a focus on interdisciplinary care. Berger et al showed that the annual direct cost of FMS patients was about US\$9,573.32. ${ }^{29}$ However, these results are already old, and more recent information for inpatient and outpatient settings is needed.

As in other studies, women are affected much more often than men. ${ }^{36-39}$ The average age of the patients in this study also corresponds to the reported results of other investigations. ${ }^{16,40}$ Length of inpatient stay was dependent on the diagnose(s) and the targets according to the G-DRG, and comparable to those of other studies and those of the calculation institute. ${ }^{26}$ As already established in other scientific studies, anxiety and depression are common concomitant diseases. ${ }^{40,41}$ The most frequent additional diagnosis was "other diseases of the musculoskeletal system", as already reported by Berger et al in $2007 .{ }^{29}$ However, we did not find a causal relationship between the number of concomitant diseases and cost, ${ }^{42}$ as was previously assumed in the literature. According to our data, disease activity and physical limitations ${ }^{43}$ are more likely to influence costs.

\section{Conclusion and limitations}

This study includes all of the costs of inpatient care for those with a severe form of FMS. As part of a cost-of-illness study, economic data analysis and its results provide important information for health-policy makers, hospital managers, and the general public. ${ }^{44}$ Moreover, it can be used as starting point for benchmarking projects and create a basis for process optimization. ${ }^{45}$ The results of the assessments clearly show, however, that severe forms of FMS are typically associated with a high number of failed treatments. The indication-based 
cost calculation can provide information for the financial risk management of an inpatient facility. For doctors, therapists, and nurses, treatment information based on the results of the concomitant disease analysis can also be generated.

Our analysis is limited by the unavailability of comparison data for standardized accounting for interdisciplinary treatment costs depending on and differentiating between intensity of FMS (especially less severe or mild cases, which were excluded here according to the inclusion criteria). Further studies should check for those and also cost related data for the elements of the treatment. In addition, further studies should look more closely at the efficacy of action taken in the context of cost causation.

\section{Acknowledgment}

The authors would like to thank the reviewers for reviewing this manuscript.

\section{Disclosure}

The authors report no conflicts of interest in this work.

\section{References}

1. Hudson JI, Goldenberg DL, Pope HG Jr, Keck PE Jr, Schlesinger L. Comorbidity of fibromyalgia with medical and psychiatric disorders. Am J Med. 1992;92(4):363-367.

2. Bennett RM. Clinical manifestations and diagnosis of fibromyalgia. Rheum Dis Clin North Am. 2009;35(2):215-232.

3. Mease P. Fibromyalgia syndrome: review of clinical presentation, pathogenesis, outcome measures, and treatment. J Rheumatol Suppl. 2005;75:6-21.

4. Sommer C, Häuser W, Burgmer M, et al. [Etiology and pathophysiology of fibromyalgia syndrome]. Schmerz. 2012;26(3):259-267. German.

5. Romeyke T, Stummer H. Multi-modal pain therapy of fibromyalgia syndrome with integration of systemic whole-body hyperthermia: effects on pain intensity and mental state - a non-randomised controlled study. J Musculoskelet Pain. 2014;22(4):341-355.

6. Lera S, Gelman SM, López MJ, et al. Multidisciplinary treatment of fibromyalgia: does cognitive behavior therapy increase the response to treatment? J Psychosom Res. 2009;67(5):433-441.

7. Suman AL, Biagi B, Biasi G, et al. One-year efficacy of a 3-week intensive multidisciplinary non-pharmacological treatment program for fibromyalgia patients. Clin Exp Rheumatol. 2009;27(1):7-14.

8. Sarzi-Puttini P, Buskila D, Carrabba M, Doria A, Atzeni F. Treatment strategy in fibromyalgia syndrome: where are we now? Semin Arthritis Rheum. 2008;37(6):353-365.

9. Sicras-Mainar A, Rejas J, Navarro R, et al. Treating patients with fibromyalgia in primary care settings under routine medical practice: a claim database cost and burden of illness study. Arthritis Res Ther. 2009;11(2):R54.

10. Gore M, Tai KS, Chandran A, Zlateva G, Leslie D. Clinical characteristics, pharmacotherapy, and healthcare resource use among patients with fibromyalgia newly prescribed pregabalin or tricyclic antidepressants. J Med Econ. 2012;15(1):32-44.

11. Thompson JM, Luedtke CA, Oh TH, et al. Direct medical costs in patients with fibromyalgia: cost of illness and impact of a brief multidisciplinary treatment program. Am J Phys Med Rehabil. 2011; 90(1):40-46.
12. Annemans L, Le Lay K, Taieb C. Societal and patient burden of fibromyalgia syndrome. Pharmacoeconomics. 2009;27(7):547-559.

13. Boonen A, van den Heuvel R, van Tubergen A, et al. Large differences in cost of illness and wellbeing between patients with fibromyalgia, chronic low back pain, or ankylosing spondylitis. Ann Rheum Dis. 2005;64(3):396-402.

14. Silverman S, Dukes EM, Johnston SS, Brandenburg NA, Sadosky A, Huse DM. The economic burden of fibromyalgia: comparative analysis with rheumatoid arthritis. Curr Med Res Opin. 2009;25(4): 829-840.

15. Wolfe F, Walitt B. Culture, science and the changing nature of fibromyalgia. Nat Rev Rheumatol. 2013;9(12):751-755.

16. Hughes G, Martinez C, Myon E, Taïeb C, Wessely S. The impact of a diagnosis of fibromyalgia on health care resource use by primary care patients in the UK: an observational study based on clinical practice. Arthritis Rheum. 2006;54(1):177-183.

17. Choy E, Perrot S, Leon T, et al. A patient survey of the impact of fibromyalgia and the journey to diagnosis. BMC Health Serv Res. 2010;10:102.

18. DRG Systems. Abschlussberichte zur Weiterentwicklung des G-DRGSystems für die Jahre 2012-2016: Klassifikation, Katalog und Bewertungsrelationen - Teil I: Projektbericht Umfang der Datenlieferung, Entgeltbereich "DRG", Datenerhebungen. [Final reports on the further development of the G-DRG system for the years 2012-2016: Classification, catalog and evaluation relations- Part I: Project report - Scope of data delivery, Remuneration area "DRG", Data collection]. Available from: http://www.g-drg.de/. Accessed January 12, 2017.

19. Gerbershagen HU, Korb J, Nagel B, Nilges P. Das Mainzer Stadiensystem der Schmerzchronifizierung: Mainz Pain Staging System (MPSS). Mainz: DRK Schmerz-Zentrum; 1986.

20. Hawker GA, Mian S, Kendzerska T, French M. Measures of adult pain: visual analog scale for pain (VAS pain), numeric rating scale for pain (NRS pain), McGill Pain Questionnaire (MPQ), Short-Form McGill Pain Questionnaire (SF-MPQ), chronic pain grade scale (CPGS), Short Form-36 Bodily Pain Scale (SF-36 BPS), and measure of Intermittent and Constant Osteoarthritis Pain (ICOAP). Arthritis Care Res. 2011;63 Suppl 11:S240-S252.

21. Aitken RC. Measurement of feelings using visual analogue scales. Proc R Soc Med. 1969;62(10):989-993.

22. Zisapel N, Nir T. Determination of the minimal clinically significant difference on a patient visual analog sleep quality scale. J Sleep Res. 2003;12(4):291-298.

23. Kroenke K, Spitzer RL, Williams JB. The PHQ-9: validity of a brief depression severity measure. J Gen Intern Med. 2001;16(9): 606-613.

24. Raspe HH, Hagedorn U, Kohlmann T, Mattussek S. Der funktionsfragebogen Hannover (FFbH): ein instrument zur funktionsdiagnostik beim polyartikulären Gelenkerkrankungen. [The function questionnaire Hannover $(\mathrm{FFbH})$ : an instrument for functional diagnostics in polyarticular joint diseases]. In: Siegrist J, editor Wohnortnahe Betreuung Rheumakranker. Stuttgart: Schattauer; 1999:164-182.

25. Kohlmann T, Raspe HH. Die patientennahe diagnostik von funktionseinschränkungen im alltag. [The patient's proximity to functional limitations in everyday life]. Psychomed. 1994;6:21-27.

26. Romeyke T, Stummer H. Interdisciplinary complex therapies in inpatient hospital treatment in Germany: evidence from Germany. $J$ Manag Marketing Healthc. 2011;4(4):208-216.

27. Häuser W. Themenheft "Fibromyalgiesyndrom - eine interdisziplinäre S3-leitlinie". [Fibromyalgia syndrome - an interdisciplinary S3 guideline]. Schmerz. 2008;22(3):239-348.

28. S3-Leitlinie: definition, pathophysiologie, diagnostik und therapie des fibromyalgiesyndroms: zweite revisionsfassung. Available from: http:// www.awmf.org/leitlinien/detail/11/145-004.html. Accessed January 12, 2017.

29. Berger A, Dukes E, Martin S, Edelsberg J, Oster G. Characteristics and healthcare costs of patients with fibromyalgia syndrome. Int J Clin Pract. 2007;61(9):1498-1508. 
30. White LA, Birnbaum HG, Kaltenboeck A, Tang J, Mallett D, Robinson RL. Employees with fibromyalgia: medical comorbidity, healthcare costs, and work loss. J Occup Environ Med. 2008;50(1):13-24.

31. Santoro MS, Cronan TA. Depression, self-efficacy, health status, and health care costs: a comparison of men with fibromyalgia or osteoarthritis. J Musculoskelet Pain. 2013;21(2):126-134.

32. Knight T, Schaefer C, Chandran A, Zlateva G, Winkelmann A, Perrot $\mathrm{S}$. Health-resource use and costs associated with fibromyalgia in France, Germany, and the United States. Clinicoecon Outcomes Res. 2013;5:171-180.

33. Doron Y, Peleg R, Peleg A, Neumann L, Buskila D. The clinical and economic burden of fibromyalgia compared with diabetes mellitus and hypertension among Bedouin women in the Negev. Fam Pract. 2004;21(4):415-419.

34. Sanchez RJ, Uribe C, Li H, et al. Longitudinal evaluation of health care utilization and costs during the first three years after a new diagnosis of fibromyalgia. Curr Med Res Opin. 2011;27(3):663-671.

35. Romeyke T, Stummer H. Economic aspects of nursing in inpatient naturopathy: evidence from Germany. Nurs Econ. 2013;31(3):137-143.

36. Wolfe F. The epidemiology of fibromyalgia. J Musculoskelet Pain 1993;1(3-4):137-48.

37. Berger A, Sadosky A, Dukes EM, Edelsberg J, Zlateva G, Oster G. Patterns of healthcare utilization and cost in patients with newly diagnosed fibromyalgia. Am J Manag Care. 2010;16(5 Suppl):S126-S137.

38. Walewski W, Szczepanski L. Epidemiological studies of fibromyalgia syndrome morbidity. Scand J Rheumatol Suppl. 1992;94:S138.
39. Haack M, Mullington JM. Sustained sleep restriction reduces emotional and physical well-being. Pain. 2005;119(1-3):56-64.

40. Arnold LM, Hudson JI, Keck PE, Auchenbach MB, Javaras KN, Hess EV. Comorbidity of fibromyalgia and psychiatric disorders. $J$ Clin Psychiatry. 2006;67(8):1219-1225.

41. Raphael KG, Janal MN, Nayak S, Schwartz JE, Gallagher RM. Familial aggregation of depression in fibromyalgia: a community-based test of alternate hypotheses. Pain. 2004;110(1-2):449-60.

42. Penrod JR, Bernatsky S, Adam V, Baron M, Dayan N, Dobkin PL. Health services costs and their determinants in women with fibromyalgia. J Rheumatol. 2004;31(7):1391-1398.

43. Rivera J, Rejas J, Esteve-Vives J, Vallejo MA. Resource utilisation and health care costs in patients diagnosed with fibromyalgia in Spain. Clin Exp Rheumatol. 2009;27(5 Suppl 56):S39-S45.

44. Lacasse A, Bourgault P, Choinière M. Fibromyalgia-related costs and loss of productivity: a substantial societal burden. BMC Musculoskelet Disord. 2016;17:168.

45. Romeyke T, Stummer H. Clinical pathways as instruments for risk and cost management in hospitals: a discussion paper. Glob J Health Sci. 2012;4(2):50-59.

46. Beer AM, Brenke R. Naturheilkundliche komplexbehandlung: welche patienten profitieren? [Naturopathic complex treatment: which patients benefit?]. MMW Fortschr Med. 2010;152(7):47-49.

47. Romeyke T, Stummer H. A study of costs and length of stay of inpatient naturopathy: evidence from Germany. Complement Ther Clin Pract. 2011;17(2):90-95.
ClinicoEconomics and Outcomes Research

\section{Publish your work in this journal}

ClinicoEconomics and Outcomes Research is an international, peerreviewed open-access journal focusing on health technology assessment, pharmacoeconomics and outcomes research in the areas of diagnosis, medical devices, and clinical, surgical and pharmacological intervention. The economic impact of health policy and health systems

\section{Dovepress}

organization also constitute important areas of coverage. The manuscript management system is completely online and includes a very quick and fair peer-review system, which is all easy to use. Visit http://www.dovepress.com/testimonials.php to read real quotes from published authors. 